\title{
Assessment of Risk Factors against Severity of COPD in Non-Smokers
}

\author{
Ashok Kumar Panjwani, ${ }^{1}$ Shaista Ghazal, ${ }^{1}$ Ravi Mahat, ${ }^{1}$ Maria Malik, ${ }^{1}$ Nadeem Rizvi ${ }^{1}$ \\ 'Department of Chest Medicine, Jinnah Postgraduate Medical Centre, Karachi, Pakistan.
}

\section{ABSTRACT}

Introduction: Chronic obstructive pulmonary disease in non-smokers has been an important concern in past decade. We studied the risk factors responsible for more severe Chronic obstructive pulmonary disease. Identifying them would help to work against progression to more severe disease as well as prevention.

Methods: A prospective cross sectional study was done in outpatient clinic of Jinnah postgraduate medical center from December 2010 to December 2011. All patients fulfilling the criteria for Chronic obstructive pulmonary disease were taken in study. Patients with less than five pack years smoking with other risk factors for Chronic obstructive pulmonary disease were evaluated.

Results: Out of total 90 patients, $74(82.2 \%)$ had mild chronic obstructive pulmonary disease and 16 $(17.7 \%)$ had moderate to severe chronic obstructive pulmonary disease. Patients with single biomass exposure were found to have mild chronic obstructive pulmonary disease except those having mosquito coil exposure. Patients with mosquito coil and wood smoke exposure were observed to have moderate to severe chronic obstructive pulmonary disease ( $p$-value 0.009).

Conclusions: Wood smokewith mosquito coil smoke exposure is responsible for more severe chronic obstructive pulmonary disease.

Keywords: biomass; chronic obstructive pulmonary disease; non-smoker; tuberculosis.

\section{INTRODUCTION}

Chronic obstructive pulmonary disease (COPD) is a major cause of morbidity and mortality worldwide. It is among top 10 global contributors to the global burden of disease as measured by disability-adjusted life years. Studies have projected that COPD, which ranked sixth as the cause of death in 1990, will become the third leading cause of death worldwide by $2020 .^{2-4}$ Tobacco smoking is established as a major risk factor, but emerging evidence suggests that other risk factors are important too, especially in developing countries. An estimated $25-45 \%$ of patients with COPD have never smoked; the burden of non-smoking COPD is therefore much higher than previously believed. About three billion people i.e. almost half the world population, are exposed to smoke from biomass fuel compared with 1.01 billion people who smoke tobacco. ${ }^{3}$ Approximately $50 \%$ of the world population uses biomass fuels (BMFs) as the primary source of domestic energy for cooking. ${ }^{4}$ The use of BMFs has been associated with indoor pollution and unsafe levels of toxic emission. 5,6 In the smoke generated by the combustion of solid fuels (wood smoke and BMFs), more than 200 chemicals and chemical compounds have been identified, $90 \%$ of which are inhalable particle matter with an aerodynamic diameter $<10 \mu \mathrm{m}$ (PM10). ${ }^{2,3}$ Most of these-including

Correspondence: Dr. Ashok Kumar Panjwani, Department of Chest Medicine, Jinnah Postgraduate Medical Centre, Karachi, Pakistan. Email: ashoka_pj@yahoomail.com. 
PM10, CO, nitrogen oxide, sulfur oxide, aldehydes (e.g. formaldehyde), polycyclic aromatic hydrocarbons (e.g.benzopyrene), volatile organic compounds, chlorinated dioxins, and free radicals-are irritants to the respiratory system..$^{7-9}$ Most of these lethal agents have been associated with infectious diseases, allergic airway diseases, and malignancy. ${ }^{7}$ Indoor air pollution is the tenth leading preventable risk factor contributing to the global burden of disease and is ranked fourth in developing countries. ${ }^{8}$ Various studies have implicated BMF smoke as one of the causes of chronic bronchitis and obstructive airway diseases. ${ }^{9-11}$ Large number of population is exposed to BMF but it has been studied less. Different biomass fuel has different composition and so as the toxins they have. Depending on exposure to different BMF, the severity of COPD would have been different. Likewise pulmonary tuberculosis, even treated one, leaves with some damage in the lungs which make it susceptible for future development of COPD.

\section{METHODS}

A prospective cross-sectional study was conducted in the Department of Chest Medicine of Jinnah Postgraduate Medical Centre,Karachi, Pakistan. Patients were recruited from outpatient clinics of tertiary care centerfrom December 2010 to December 2011. After initial inquiry of symptomatology, spirometry was performed. All those patients who fulfilled the criteria for COPD were taken into the study with written consent. Patient with more than five pack years smoking history were excluded from study. Total 90 patients with positive exposure to wood smoke, animal dung, mosquito coils and/or kerosene oil were evaluated for severity of COPD using spirometry results, and the Medical Research Council (MRC) grading for dyspnea. COPD (FEV1/FVC < 70\%) was classified as mild (FEV1 $\geq 80 \%$ predicted) or moderate to severe (FEV1 23 to $79 \%$ predicted). ${ }^{9}$

All data was entered in SPSS v.17 for analysis. Frequency \& percentage was calculated for categorical variables like COPD frequency, severity of COPD, age groups, gender, exposures, risk factors, etc. Chi-square $\&$ fisher exact test was used to get the association of variables and severity level of COPD. P-value $<0.05$ was considered as statistically significant.

\section{RESULTS}

Out of total 90 patients, 46 were male and 44 were female. Of them, 74 patients were with mild COPD and 16 were with moderate to severe COPD. Sufferers were evaluated on the basis of single or multiple risk factors. Most subjects with single exposure were found to have mild COPD except those having mosquito coil exposure. When severity of disease was analyzed on the basis of multiple risk factors, the subjects having mosquito coil and wood smoke exposure were seen to have severe COPD ( $p$-value 0.009). An important correlation was found between severe COPD and history of tuberculosis.

\section{DISCUSSION}

Smoking is the commonest risk factor for COPD. But in many developing countries like Pakistan and India, high prevalence of COPD is additionally attributed to biomass fuel exposure, ${ }^{10}$ as the use of these for cooking and heating purposes is very common in these countries.

COPD is mostly thought to be a disease affecting males more as compared to females but it is alarming to note that according to some studies, nonsmoker COPD is more prevalent in females, being explained by their exposure to BMFs. ${ }^{17}$ In contrast, the study done by Buist et al showed higher prevalence of this in males. ${ }^{11}$ The risk of moderate-to-severe disease was seen markedly associated with male gender in another study. ${ }^{17}$

A study done in China reported COPD in nonsmoking males being related to BMFs used for cooking, partially explained by the persistent higher levels of pollutants in living and sleeping areas of the home. ${ }^{12}$

We did not find significant gender predisposition in our study. Also both males and females had equal presentation in moderate to severe disease group. This observation can be explained by the nature of living conditions as most of our patients belong to lower classes having small homes with no proper ventilation, which can result in increased exposure of all house hold members to pollutants produced from BMFs and mosquito coils, commonly used in homes.

Smoking is the major cause of COPD, but exposure to biomass fuels and tuberculosis are important additional factors. ${ }^{13,14}$ Moreover, exposure to biomass itself is associated with tuberculosis. ${ }^{15}$ Our study showed significant association of pulmonary TB with moderate to severe COPD. Surprisingly we noted that $3 \%$ patients who suffered TB twice in the past had mild instead of more severe form of COPD (Table 2). 


\begin{tabular}{|ll|}
\hline \multicolumn{2}{|l|}{ Table 1. Classification of severity of COPD. } \\
\hline Severity of COPD & N (\%) \\
Mild (FEV1 $\geq 80 \%$ predicted) & $74(82.2 \%)$ \\
Moderate to Severe (FEV1 23 to $79 \%$ & $16(17.8 \%)$ \\
predicted) & 90 \\
Total & \\
\hline
\end{tabular}

\begin{tabular}{|c|c|c|c|c|}
\hline \multirow[b]{2}{*}{ Variables } & & \multicolumn{3}{|c|}{ Severity of COPD } \\
\hline & & $\begin{array}{l}\text { Mild COPD } \\
(\mathrm{n}=74)\end{array}$ & $\begin{array}{c}\text { Moderate } \\
\text { to Severe } \\
\text { COPD } \\
(n=16)\end{array}$ & P-Value \\
\hline \multirow{5}{*}{$\begin{array}{l}\text { Age in } \\
\text { years }\end{array}$} & $<40$ & $8(11 \%)$ & $2(12.5 \%)$ & \multirow{5}{*}{0.638} \\
\hline & $\begin{array}{l}40 \\
50\end{array}$ & $22(30 \%)$ & $4(25 \%)$ & \\
\hline & $\begin{array}{l}51- \\
60\end{array}$ & $24(32 \%)$ & $8(50 \%)$ & \\
\hline & $\begin{array}{ll}61 & - \\
70 & \end{array}$ & $18(24 \%)$ & $2(12.5 \%)$ & \\
\hline & $>70$ & $2(3 \%)$ & 0 & \\
\hline \multirow{2}{*}{ Gender } & Male & $38(51 \%)$ & $8(50 \%)$ & \multirow{2}{*}{0.922} \\
\hline & Female & $36(49 \%)$ & $8(50 \%)$ & \\
\hline \multirow{3}{*}{$\begin{array}{l}\text { Occurance } \\
\text { TB }\end{array}$} & No Tb & $43(58 \%)$ & $4(25 \%)$ & \multirow{3}{*}{0.032} \\
\hline & Once & $29(39 \%)$ & $12(75 \%)$ & \\
\hline & Twice & $2(3 \%)$ & 0 & \\
\hline
\end{tabular}

This may be related to presence of multiple risk factors in the group having more severe form of disease although it is difficult to draw any conclusion from this observation as numbers of patients were just two. However, study by Hnizdo etal. showed estimated average chronic deficit in FEV1 after one, two, and three or more episodes of pulmonary tuberculosis was $153 \mathrm{ml}, 326 \mathrm{ml}$, and $410 \mathrm{ml}$, respectively. ${ }^{16}$ To see association of severity of COPD in patients having TB multiple times, more comprehensive studies with larger sample sizes need to be undertaken in our setup.

Another observation made in this study was that wood smoke and mosquito coil together were mostly related to moderate to severe disease as compared to other single and multiple risk factors. Burning one mosquito coil would release the same amount of particulate matter $<2.5 \mu \mathrm{m}$ in diameter mass as burning 75137 cigarettes. ${ }^{17}$ This is a very important observation because both wood smoke and mosquito coils are of common use in households in Pakistan, especially among underprivileged population and to control the burden of disease due to COPD this issue needs to be addressed.

No patients in our study were exposed to kerosene/gas so no comment can be made about its association with COPD in our population. Some studies have evidenced associations of COPD with gas/kerosene fuel use for both heating and cooking. In UK, decrements in FEV1 $(-70 \mathrm{~mL})$ and in FVC $(-35 \mathrm{~mL})$ have been observed in young adults using gas fuel when compared to those using electricity for cooking. ${ }^{18}$

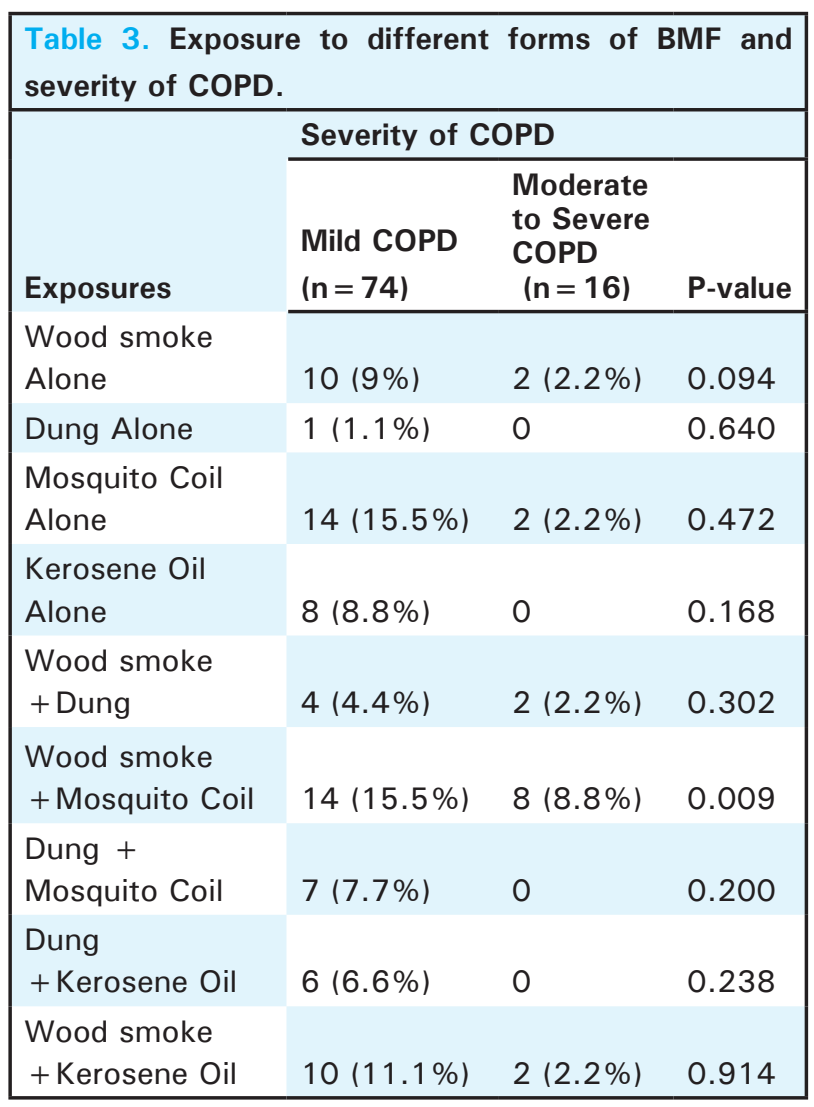

\section{CONCLUSIONS}

This study shows the association of nonsmoker COPD to biomass fuel especially wood smoke and mosquito coils and increased severity of COPD. Tuberculosis was also found to have significant association with moderate to severe form of COPD.

COPD is a preventable disease as many risk factors are modifiable. Although people are aware about hazards of cigarette smoking, they do not have much knowledge regarding harmful effects of biomass exposure which has been proven by many studies. In order to control the burden of disease secondary to nonsmoker COPD, steps need to be undertaken to spread public awareness regarding this issue. 


\section{REFERENCES}

1. Lopez AD, Mathers CD, Ezzati M, Jamison DT, Murray CJ.Global and regional burden of disease and risk factors, 2001: systematic analysis of population health data. Lancet. 2006 May 27;367(9524):1747-57.

2. Lopes AD, Shibuya K, Rao C,Mathers CD, Hansell AL, Held LS, et al. Chronic obstructive pulmonary disease: current burden and future projection. Eur Respir J. 2006 Feb;27(2):397-412.

3. Salvi SS, Barnes PJ. Chronic obstructive pulmonary disease in non-smokers. Lancet. 2009 Aug 29;374(9691):733-43.

4. World Health Organization. Fact sheet N²92 - June 2005 Indoor air pollution and health. [Internet]. Geneva: World Health Organization; 2005 [cited 2009 Dec 11]. Available from: http:/ / www.who.int/mediacentre/factsheets/fs292/ en/index.html

5. Torres-Duque C, Maldonado D, Pérez-Padilla R, Ezzati M, Viegi G; Forum of International Respiratory Studies (FIRS) Task Force on Health Effects of Biomass Exposure. Biomass fuels and respiratory diseases: a review of the evidence. Proc Am Thorac Soc. 2008 Jul 15;5(5):577-90.

6. Viegi G, Simoni M, Scognamiglio A, Baldacci S, Pistelli F, Carrozzi L, et al. Indoor air pollution and airway disease. Int J Tuberc Lung Dis. 2004;8(12):1401-15.

7. Fullerton DG, Bruce N, Gordon SB. Indoor air pollution from biomass fuel smoke is a major health concern in the developing world. Trans $\mathrm{R}$ Soc Trop Med Hyg. 2008;102(9):843-51.

8. World Health Organization.The World Health Report 2002: reducing risks, promoting healthy life. [Internet]. Geneva: World Health Organization; 2002 [cited 2010 Jan 2]. Available from: http:/ / www.who.int/whr/2002/en/whr02_en.pdf
9. Behrendt CE.Mild and moderate-to-severe COPD in nonsmokers: distinct demographic profiles. Chest. 2005 Sep;128(3):1239-44.

10. Akhtar T, Ullah Z, Khan MH, Nazli R. Chronic bronchitis in women using solid biomass fuel in rural Peshawar, Pakistan. Chest. 2007 Nov;132(5):1472-5.

11. Buist AS, McBurnie MA, Vollmer WM, Gillespie S, Burney P, Mannino DM, et al. International variation in the prevalence of COPD (the BOLD Study): a population-based prevalence study. Lancet. 2007 Sep 1;370(9589):741-50.

12. Zhou Y, Wang C, Yao W, Chen P, Kang J, Huang S, et al. COPD in Chinese nonsmokers. Eur Respir J. 2009;33(3):509-18.

13. Abdool-Gaffar MS, Ambaram A, Ainslie GM, Bolliger CT, Feldman C, Geffen L, et al. Guideline for the management of chronic obstructive pulmonary disease--2011 update. S Afr Med J. 2011;101(1 Pt 2):63-73.

14. Allwood BW, Myer L, Bateman ED. A systematic review of the association between pulmonary tuberculosis and the development of chronic airflow obstruction in adults. Respiration. 2013;86(1):76-85.

15. Prasad R, Singh A, Garg R, Giridhar GB. Biomass fuel exposure and respiratory diseases in India. Biosci Trends. 2012;6(5):219-28.

16. Hnizdo E, Singh T, Churchyard G. Chronic pulmonary function impairment caused by initial and recurrent pulmonary tuberculosis following treatment. Thorax. 2000 Jan;55(1):32-8.

17. Liu W, Zhang J, Hashim JH, Jalaludin J, Hashim Z, Goldstein BD. Mosquito coil emissions and health implications. Environ Health Perspect. 2003 Sep;111(12):1454-60.

18. Moran SE, Strachan DP, Johnston ID, Anderson HR. Effects of exposure to gas cooking in childhood and adulthood on respiratory symptoms, allergic sensitization and lung function in young British adults. Clin Exp Allergy. 1999;29:1033-41. 